\title{
SCIENCE
}

$\frac{\text { FridaY, MARCH 25, } 1921}{\text { CONTENTS }}$

Plants and Plant Culture: CharLes V. PIPER. 269
Scientific Events:-

The Carnegie Trust for Scottish Universities; Meeting of the Organizing Committees of the Sections of the British Association; The Personnel Research Federation; Grants for Research made by the American Association for the Advancement of Science ..... 279

Scientific Notes and News ............ 282

University and Educational News 286

Discussion and Correspondence:-

The Preglacial Outlet of Lake Erie: Dr. G. Frederick Wright. The Conservation of Game and Fur-bearing Animals: ProFESSOR HENRY B. WARD. Relativity and Estimates of Star Diameters: DR. REGINALD

A. Fessenden 286

Scientific Books:-

Wilder's Laboratory Manual of Anthropometry: Dr. George Grant MacCurdy.... 288

The Production of Biological Stains in America: DR. H. J. Conn .............. 289

Special Articles:-

The Static Atom: Dr. Irving Langmuir... 290

The Ollahoma Academy of Science: L. B. NICE. 293

The Western Society of Naturalists-Northwest Section: GEO. B. RIGG ........... 29

MSS. intended for publication and books, etc., intended for review should be sent to The Editor of Science, Garrison-onHudson, N. Y.

\section{PLANTS AND PLANT CULTURE ${ }^{1}$}

THE enthusiasm resultant from the successful establishment of Botanical Abstracts by the combined efforts of all Americans interested in plants and plant culture has tended to revitalize the belief that a closer union of all scientific societies concerned with plants is a desideratum of great importance. In this connection the solidarity of chemistry and the consistent efforts of chemists to ally their science with industry is contrasted with the very different state of affairs that exists in botany. Another new influence of unifying tendency is the National Research Council, which, rather defying tradition, has combined in one division all of biology and agriculture. Besides it is attempting to bring about greater cooperation of research institutions and to amplify scientific activities by securing support from commercial and other sources. There still exist men who earnestly decry the economic tendencies of science and consider such argument, either as justification or for support, to be futile or dangerous. Whatever appeal there may be to botany and correlative sciences in the phrase "research for research's sake," it is Quixotic to expect it to be effective in such fields of effort as medicine, engineering and agriculture, where the relations to health, industry and prosperity are obvious.

If there is to be adopted a broader view of plant science, one that is to embrace all of conventional botany as well as plant culture, it is manifestly important that there be full discussion of the desirability of such amalgation as well as of the causes that have led to the existing state of affairs. There is apparently need of considerable readjustment of

1 Address in the joint program of the American Society of Agronomy, Botanical Society" of America and American Phytopathological Society, Chicago, December 30, 1920. 
mental attitudes if the influences that have been so potent in the past are to be made. nugatory.

It so happens that during the past decade or so there have been many discourses published, mostly in Sorence, on the general theme "What is the matter with botany?" The diverse viewpoints of experienced men have been set forth in detail, so that it is relatively easy to grasp their attitudes toward the problem. So far as I know these essays have called forth little in the way of comment from plant culturists either as expressions of sympathy or as opinions that might help in the diagnosis of the case. Now the whole matter has again come to the front, even to the extent of definite ideas to organize a broad American Plant Society that will embrace in its membership all concerned with plants or their culture. It would seem therefore that agronomists and other plant culturists can scarcely refrain longer from presenting their viewpoints as to the nature of the centrifugal forces that have kept botany and plant culture apart. Inasmuch as many botanists have attempted to define what agriculture is and what it is not, is high time that there be a rejoinder, lest silence on the part of agronomists and horticulturists be construed as assent to the statements that have been made.

A survey of the many articles by botanists in relation to the existing conditions shows that one or another of them has recognized several of the tendencies that have been more or less potent. Not unnaturally some of these tendencies or factors will be evaluated by the plant culturist quite differently from the botanist. The factors that are adduced are in part historical or traditional; in part the concomitant of intellectual isolation; and to some extent the result of conventional or even cramped ideas concerning the definition of the word science and of such phrases as pure science and applied science. Historically the development of plant culture has been almost without contact with botany or the study of plants as plants. The beginnings of plant culture go far back in the history of man, long before there were historians to record the facts or scientists to ponder over their significance. Witness the extraordinary development of maize, beans, tobacco, and other plants by the American Indian, so great indeed that the wild originals are no longer known or at least recognized as such; the marvelous series of varieties or sorghums originated by the African negroes; the endless forms of rice brought into existence by the Indo-Malayan peoples; the high development of wheat and other small grains in prehistoric times. Primitive man was indeed a wizard, agriculturally considered. Not only did he discover each and every important food plant, as well as all narcotics and stimulants, but most of them he cultivated and by one means or another developed numerous varieties. From prehistoric man we inherit not alone a wealth of crop varieties but more or less definite knowledge of cultural methods. From this foundation modern plant culture has been developed by farmers, gardeners, agronomists and horticulturists by an almost infinite amount of " cut and try." Practically all of the progress in tillage, manuring, drainage, irrigation, breeding, pruning, has thus been obtained.

It may be that underlying the historical relations or lack of relations between botany and plant culture is what one botanist refers to as "intellectual isolation," "provincialism," and as a "feeling of superiority." Perhaps the wit's definition of a professor of botany carries the same import as does the phrase "intellectual isolation." "A professor of botany is a man who teaches what he knows about plants to young men and women who expect to instruct students who desire to become professors of botany to train others to teach." This definition suggests what the doctors call a vicious circle rather than the society ideal called a "select circle."

Inasmuch as a prominent botanist used all of the quoted expressions, it may be permissible to divulge an open secret among agronomists and horticulturists, namely, that the last one especially, the "feeling of superiority," has long been recognized as an important element in preventing more cordial 
relations between conventional botanists and plant culturists. In the recent articles that I have referred to, several of the writers contrast such subjects as agronomy, horticulture, forestry, with botany, manifestly implying that the former are no part of botany. The omission of the mention of any branch of plant culture in other articles would also justify the deduction that they are excluded subjects. On the other hand a few botanical writers point out that it is the great weakness of conventional botany that it has held aloof from the culture of plants as a proper field of its activity; deplore the fact that botany has been restricted mainly to impractical considerations and that the practical uses of plants have largely been segregated in other fields of endeavor. Curiously enough, botany has always displayed a more cordial attitude toward pharmacy and forestry than it has towards horticulture or agronomy. Perhaps drugs and trees smack less of the farm than do soils, manures, and crops. It may be related to that curious human tendency, especially of the city dweller, to expend wit on the tiller of the soil; a peculiar mental trait that has given a sinister or derogatory meaning to such originally innocent terms as villain, heathen and pagan.

Whatever the causes may have been, it has come about that botanists get a very different training from agronomists and horticulturists. It is a trite saying that botanists know nothing about plant culture and agronomists and horticulturists little about botany. Individuals fairly proficient in both are all too scarce. We are thus perpetuating in our schools the schism that exists between the two groups of men who devote their energies to problems concerning plants. It is comforting to believe that more and more of us are coming to realize that this is truly deplorable. I can well appreciate a consuming interest in plants solely on account of the wonderous diversity of their forms: of the extremely interesting phenomena in their growth and movements; of their complex relations to each other and to their physical environment; of the intricacies of their cellular structures and functions; but the practical world is more interested in plants as sources of food, raiment and other necessities. While it is perfectly true that mankind can not live by bread alone, it is equally true that if he does not provide for bread he will very soon be freed from all other cares and desires.

This separation of botany from plant culture is, as already pointed out, tacitly admitted in numerous recent articles. It is likewise evident enough in text-books. In Pfeffer's "Physiology of Plants," for example, whenever the subject-matter impinges on plant culture, the student is referred to Mayer or some other agricultural text. It is related of a famous German botanist that when a student asked the name of a particular cultivated plant, he replied: "How should I know? Ask the gardener." Perhaps some of the inexcusable misidentifications of plants in recent technical articles were due to asking the gardener. Some exceptions to this narrow attitude conspicuous on account of their rarity do indeed occur among botanists where men were interested in the relation of their discoveries to plant culture. I refer to such men as Gaertner, Sachs, Miller, Don, as a few examples.

Again, there are some current ideas concerning the nature of science and its conventional divisions, pure science and applied science, that need to be dispelled and if possible corrected.

Some of my botanical friends would at once protest at the title of my address, and suggest that it would better be "Plant science and plant culture," arguing. in this wise: plant science or botany is the whole knowledge of plants that has been accumulated and is systematized and formulated in respect to all the general principles that have been discovered; whereas plant culture is purely an art, to a large extent the result of the application of botanical principles. As printed evidence I quote from one of the botanical writers:

Agriculture, for example, is not a science, but an art, and whatever of science it employs is ap- 
plied from botany, zoology, geology, climatology and so forth.

The implication conveyed in designating plant culture as an art is presumably that a science is something intellectually higher. Of course, this is a mere matter of definition of terms. Someone has proposed the definition: Science is "finding out and learning how and why." So broadminded a man as Huxley once gave his views of science as follows:

To my mind, whatever doctrine professes to be the result of the application of the accepted rules of inductive and deductive logic to its subjectmatter: and which accepts, within the limits which it sets itself, the supremacy of reason, is science.

There is in this definition no trace of restriction as to what the subject-matter may be. It pertains quite as much to plant culture as to plant morphology, to goats as well as sheep. A restricted definition that classifies knowledge of plants as science and disposes of knowledge of plant culture as nonscience, has not been a solidifying influence among plant workers.

The attempts to divide science on the basis of quality or usefulness have been in the main very unfortunate as in most cases one of the subsidiary terms involves a disparagement; thus pure science and applied (by implication impure) science; fundamental and superficial; practical and theoretical (by suggestion impractical) science; philosophical and practical science. Some of the terms suggest that they were invented by snobbish persons, but others seem sincere efforts to distinguish purely pragmatic knowledge from that which rests on a philosophical or theoretical basis. It would make for greater solidarity, I imagine, if instead of making distinctions that concern persons as well as things, we should emphasize "science in the service of humanity" or "science the handmaid of progress."

If we must persist in the attempt to distinguish two sorts of science I would suggest empirical and philosophical. The former would include in the main information based purely on observation or on test, as long as the underlying causes are unknown or vague, and which some writers delight to call " mere empiricism"; the latter to the knowledge which is illuminated by proven theory or broad inductive generalizations. I suspect it is the mental satisfaction derived from knowing something of the why and the how that tends to make us regard philosophical science as something more to be esteemed than is information of facts regarding the underlying causes of which we are either entirely in the dark or guess at vaguely. It is much as though we praised ourselves unduly when we solved wholly or in part one of nature's puzzles, and called the other fellow stupid because he could not unfold his problem. It is perhaps well to be modest and to realize that some riddles are much more difficult than others.

But the phrases "pure science" and "applied science" have involved other unfortunate consequences even to the confusion of thought. "Applied science" is conceived by some writers to imply the employment of definite known scientific truths or principles. In the words of one writer, "You must have your science before you can apply it." If this statement be true, there is very little of applied science in plant culture, or indeed in all agriculture. It is safe to say that 90 per cent. of what is known of practical methods in the culture of plants is almost purely empirical, and has been gained by an enormous amount of observation in actual trials. This information is nevertheless real knowledge as measured by the best of standards; it works in practise, however little we may know about the underlying causes or factors. The repeated assertions to the effect that the major part of agriculture is something applied from botany, chemistry, geology and what not is one that I wish emphatically to contradict. I have no hesitancy in stating that 90 per cent. of the garnered knowledge of botany in the traditional sense has no obvious relation to plant culture, and most of it has little conceivable relation. Another writer asserts,

It is the pure or fundamental science that keeps applied seience alive, that makes progress possible. 
An obvious rejoinder is that is is the applied science that keeps the investigator alive. So far as plant culture is concerned, it existed thousands of years before there were such a thing as pure or fundamental science, unless I mistake what is meant by this phrase. Clearly the quotation asserts too much, if plant culture is part of "applied science."

The statement that plant culture is made up largely of botany is objectionable, first of all because it is offensively patronizing and second because it is to a great extent not true. The plant culturist, be he agronomist, horticulturist, forester, or what not, is concerned first of all in the methods that make for the successful culture of a plant, and secondarily in the factors or factor complexes that affect quantity or quality of yield. Yield, including the underlying factors, is the central consideration in plant culture, but the word yield is seldom seen in a botanical text-book. In the culture of crops there are four major series of factors that affect yield, namely, the adaptations of the plant, the quality of the soil, the climatic factors, the cultural or artificial factors. It is a fair assumption that if the best adapted variety be planted on rich soil and intelligently cultivated the highest yields are to be expected if the weather condition are favorable and pest injury reduced to a minimum. It is worth while considering briefly just how much we know concerning the relation of yield to a few of the factor complexes mentioned.

Consider first the plant and its habits, or if you prefer its ecological adaptations. Undoubtedly primitive man, like the modern grower of orchids, attempted when he first cultivated a plant to imitate its natural habitat. He certainly did not plant rice on the dry hilltops nor wheat in the marshes. But what after all do we know about these habital adaptations save by observation. No sensible man would expect to succeed with bananas outdoors in New England. But just why is it, if you please, that bananas can not stand as much cold as apple trees? Or consider a simpler case, namely winter wheat and spring wheat, perhaps representing the broadest extremes in a single species of physiological adaptation in relation to temperature that has been developed in plant culture. Just why does the one endure much lower temperatures than the other? It would seem practically certain that the differences are not due to any morphological character, since similar phenomena occur in naked organisms; therefore, it is nearly certain the differences in adaptation lie in the protoplasm. But it must be admitted we have not even a working hypothesis as to the nature of the machinery.

Again consider the behavior of some introduced plants with that of others brought from the same region. Bluegrass, redtop and white clover have spread over all of the northeastern fourth of the United States and tend quickly to occupy all cleared and untilled land; in other words, they spread aggressively. In contrast, certain other common European grasses can barely exist or do not thrive at all. Crested dog's-tail is rather a botanical rarity in the United States notwithstanding that thousands of pounds of seed are sown annually, just because the English consider it a good grass. Still more remarkable is Weingartneria canescens, a grass the viable seed of which is an abundant impurity in certain European seeds, but no one has ever found a specimen of the plant in the United States. Japan clover, introduced accidentally about 1853, has spread over all the south. The lowland ranges of California are covered with grasses and other herbs, 80 per cent. of the bulk of which is made up of Mediterranean plants. On the foothills of the Himalayas the Mexican dahlia escaped cultivation and now covers miles of the mountain sides. In Ceylon and Java an extremely aggressive and abundant sunflower-like plant is Tithonia diversifolia, which in its native home near Acapulco, Mexico, is a very restricted rather rare plant. Many other cases might be cited. Why are some of these introduced plants so aggressive and others so impotent? It is an evident fact and a clear problem of much importance agriculturally. All that we can postulate is that as a rule an introduced plant that is aggressive comes from a region 
with closely similar climatic conditions. Rarely a native plant shows similar aggressiveness like ragweed in the north and Eupatorium capillifolium in the south. Various hypotheses have been advanced to explain the aggressiveness of weeds, but they are simply hypotheses. Certainly attempts to find a correlation between weediness and abundance of seeds produced has proved a dismal failure. Nor has any better success been achieved toward understanding the contrasting phenomenon of dwindling or "petering-out."

The distribution of the species of a genus -let us say the oaks of the United States-is an interesting phenomenon. But why is one species circumscribed thus and another delimited so? To say the species have different adaptations is merely stating the fact in other words. If we are honest, we must admit, I think, our complete ignorance. Now these are samples of a great group of phenomena that confront students of cultivated plants. They must very properly, I think, also be considered problems of ecological botany. But the ecology of the botanists has not thus far developed enough to be an asset to the plant culturist. The details of pond margins, mountain tops, and seashore strand throw no light on why maize or potatoes or wheat thrive better in some situations than in others.

Now we come to soils. Surely chemical and botanical science have here rendered signal service to plant culture. Here again it is well to consider primitive plant culture. Undoubtedly our prehistoric ancestors must have observed the greater luxuriance of plants on certain soils, about dung droppings and on landslides. Certain it is that long ago many uncultured tribes had learned to use dung, ashes, fish, leaf mold, seaweeds, and other substances to increase yields. One of the early results. achieved by chemists and botanists was to determine the chemical elements necessary to plant life. Eventually from this developed the idea that all of these necessary elements were amply abundant everywhere except nitrogen, phosphorus and potash. And very naturally substances containing these elements were sought out to use as fertilizers.
The history of the development leading up to the conclusion stated and its general adoption, was by no means simple. On the agricultural side the great exponent was Liebig. But one can not to-day read Liebig's numerous works without realizing how much he floundered in the maze of conflicting facts and theories and the many errors into which he was led. In his combatting of the old humus theory of plant nutrition he denied any value whatever to humus except to supply carbon dioxide, but in spite of his teachings the German farmers refused to abandon the use of dung and compost. Liebig also clung to the idea that nitrogen was of no avail as a fertilizer, as the atmosphere furnished abundant supply. One of the controversies over nitrogen was finally solved by Helriegel and Wilfarth, who established the fact that legumes by the aid of root nodules were able to utilize atmospheric nitrogen. This is one of the striking landmarks of agricultural science, but it is well to remember that the practical effect of legumes in rotation was well known to the Romans and other ancient peoples. In Hartes "Husbandry," published in 1764, is written:

All plants that bear leguminous flowers (as lucerne, sacrifoin, trefoils, vetches, etc.) enrich the ground and of this the husbandman has daily experience in the eulture of clover.

In its final evolution the Liebig theory of soil fertility came to mean that the productivity of a soil was primarily determined by the quantity and availability of the nitrogen, phosphorus and potash which it contained. Indeed many modern writers identified these three substances as fertility.

Curiously enough, almost any experienced farmer will express an opinion after examination as to the quality of a soil. His standards of measurements are about as follows: Soils decrease in productivity based on correlation with texture in about this sequence-clay loams, loams, silt loams, clays, fine sands, coarse sands, gravel; and in color in about this order-black, brown, red, yellow, gray, white. His judgment is therefore based in part on texture and in part on color. Crude 
as this basis of measurement may be, it certainly has some correlation with productivity. Indeed it may be said that chemical methods of soil examination resulted in a great neglect of the study of the more obvious characteristics. Unquestionably the best index of the quality of a soil is its productivity in crops. Analyses of soil from good spots and from poor spots in the same field have sometimes revealed no differences. This fact and others led to the concept that productivity might be lessened not only by the absence of a necessary element but the presence of a deleterious agent, and that fertilizers were in some cases at least substances that inhabited the injurious factor. It is a long story to consider this subject, but viewed purely as a theory it can explain some things not clarified by the plant food theory. It is well to remember that many investigators who considered the effects of nitrogen, phosphorus and potash as due solely to additional plant food, nevertheless regarded the effects of lime as partly at least due to overcoming an unfavorable factor, and the action of still other materials as stimulants, without clearly defining what they meant by stimulants. The available facts were simply the addition of the substance and the end reaction of the plant. The different rôles postulated are in the main hypotheses, and the existing body of facts certainly is insufficient to prove any one of the simple theories. A broader view now coming to be widely held is that the soil is a complex of very numerous factors, good, bad, or indifferent so far as a particular plant is concerned, and the end result measured in yield is the balance of the conflicting factors. To state it in another way productivity is probably quite as much influenced by qualititative soil differences as by quantitative diversities-but the theory that has generally been accepted is purely quantitative. Such a view of "soil fertility" which it must be admitted can now be measured only in terms of yield, means that it is comparable in scope to "weather" as applied to the seasonal complex of climatic factors. The actual knowledge that we have of soil productivity and of fertilizers is therefore still almost wholly empirical. The extension and clarification of this knowledge is, it seems, most likely to be obtained by a much more intimate knowledge of the plant reactions to each of the soil factors that can be controlled and the different combinations of these factors. An exceedingly interesting recent contribution is that of Bottomley, who presents strong experimental evidence to show that highly organized green plants must have dead organic matter as part of their food.

The effects of one crop upon another often very marked, sometimes beneficial, more often injurious. The nature of these effects is very obscure, but it now seems clear that it can not be wholly related to the quantitative supply of plant food. These phenomena have been used to lend support to the theory that yields are often greatly reduced by the presence of deleterious substances, in this case supposed to be excreted by the preceding crop. The theory is attractive in its simplicity and there is some evidence in its favor, but there is no clear proof that plants do excrete repellant substances. The curious way in which certain wild plants occupy areas to the complete or nearly complete exclusion of other species might well be due to such a factor. The effect of one plant upon another is an old observation in plant culture, and appears in botanical literature as early as Von Mohl. It is only in recent years that the actuality of the fact is established beyond doubt. An understanding of its basic causes is manifestly a matter of great importance. At the Rhode Island Experiment Stations, onions varied in yield from 13 bushels to 412 bushels per acre in a long series of plots, the differences being due solely to the effects of the preceding crops.

The subject of tillage is likewise one much involved. The simplest plant culture requires some disturbance of the soil, even if only to remove stones or roots. But different methods or different degrees of stirring the soil, show marked effects on subsequent yields. So great are these differences that the famous Jethro Tull proclaimed the slogan "Tillage is 
manure," meaning that the same end results could thus be obtained. Why? There is a bewildering array of hypotheses as to why tillage tends to increase yields, including better mechanical conditions; improved aeration; increased nitrification; additional carbon dioxide; mixing of the soil; elimination of weeds; and in dry regions particularly conservation of moisture. There may be and probably is some truth in all of these explanations but exact data on any of them are far from abundant. The really definite knowledge is empirical, namely, that tillage methods do tend to increase yields.

The breeding of plants has been a most potent factor in securing larger and better yields. Our knowledge of genetic phenomena has been enormously increased in recent years from the activity incited by the rediscovery of Mendel's law. The effect of this greatly increased knowledge of genetics has inspired many immoderate statements as to its effect on agriculture. Thus one writer says "Through scientific work in the study of heredity, we have learned to multiply the races of our useful plants so that they may fit in more exactly to the variable conditions in which plants must be grown," and that Mendel's law "is the basis of most of our work in the study of heredity and this in turn has made agriculture scientific." It is pleasing to learn that a bit of leaven like this is able to uplift all agriculture into the condition called scientific, while presumably it was before something different. As a matter of fact, the practical value of Mendelian knowledge to plant breeding is disappointingly small. Witness the innumerable improved varieties in all our cultivated plants long antedating Mendel. Consider the lilies, the roses, the chrysanthemums, the carnations, the tulips, indeed, any plant much cultivated, and ponder upon the infinite amount of work that led to their development-all without the guidance of any scientific theory. This admission does not discount the tremendous value of the new knowledge of genetics which gives us so great an insight into the factors involved in plant variations.
The nature of plant diseases and the methods discovered for their control is a contribution to plant culture for which the botanists of the schools may rightly claim large credit. This is clear in spite of the fact that farmers and gardeners had before the day of plant pathologists found out the efficacy of bluestone for wheat smut and sulphur for mildew; and against other diseases had developed resistant or immune varieties. The development of phytopathology is an index, I believe, of what might well happen in other fields of plant culture, if trained botanical workers will wholeheartedly engage in its problems and avoid being attracted more to the purely scientific problems than to those of cultural import.

The climatic complex of factors is difficult to evaluate. Numerous attempts have been made to correlate growth and yield with the curves of temperature and of moisture precipitation and even specifically to outline the limits of the future extension of wheat culture northward. Thus far these attempts have not thrown any great light on the problems of climatic adaptations.

I must not omit, however, the recent illuminating contribution of Garner and Allard, who have discovered the remarkable reactions of plants to the length of daily illumination. Any one who has cultivated plants has come to realize the extraordinary way in which they behave under different conditions, one might say the vagaries which they exhibit. One of these is the manner in which most plants speed up their maturing in fall. The farmer says the plant is hurrying to get ripe before frost. Several vague theories were current among plant culturists as to the cause of this phenomenon, one that the stimulating factor was the increasing difference between day and night temperatures, another that it was due to the increased temperature of the soil. It is remarkable to how high a degree the temperature factor was assumed in every periodic phenomenon. Garner and Allard have accumulated a mass of experimental data that leave no room for doubt that the stimulating factor is associated with the daily length of 
illumination. Indeed it may be hazarded that it is this stimulus which normally controls all recurrent periodic phenomena in plants and animals. Just how it is to be correlated with certain other phenomena which form the basis of Kleb's salts-carbohydrate theory is not yet clear. It is quite possible that entirely different stimuli affect the control of vegetative and reproductive phenomena so as to give similar end reactions. The GarnerAllard factor certainly provides a new method of approach to study the internal factors that control the plant's activities. It is probably not a wild guess that these internal factors are as numerous as the genetic factors concerned in the plant's heredity mechanism. As it happens, the approach to this problem and the progress made in its solution was purely from the agronomic viewpoint and with the object of solving an agronomic puzzle. This is worthy of mention as an illustration of the fact that the plant culturist gets a different contract with plant phenomena from the botanist of the laboratory.

The plant culturist has long been familiar with the phenomena illuminated by Garner and Allard. It is this factor which in the case of field crops led to date of seeding trials -by which in a purely empirical way the best date of seeding or planting for each locality was determined. Any one who has seen plots of millet, for example, planted at succeeding dates will appreciate how much this factor alone can affect yields.

Another important factor affecting yield is the spacing of the plants whether secured by rate of seeding or by planting at measured distances. It is easy to understand why too sparse seeding will reduce yields and also to comprehend that crowding may result unfavorably-but it is doubtful if any other method than actual trials will ever enable us to ascertain the optimum rate of spacing for any particular crop at any specific place. Curiously enough as Mooers has shown, varieties of maize not markedly unlike have very different optima as regards spacing. In southern India where rice culture is very ancient, and the seedlings are transplanted by hand, Wood was able to increase yields materially by determining the optimum spacing distance. Incidentally this greatly reduced the amount of seed necessary which in a country where the daily wage is eight cents was a considerable economic factor. Such empirical data as these are highly important in plant culture-and it seems not unlikely that they always will have to be determined by test and not by some mathematical equation.

In America, crops are mostly planted as pure culture, in India usually as mixed cultures, one of the plants commonly a legume. Mixed cultures usually outyield pure cultures -but except where the crops are garnered by hand, the increased cost of harvesting becomes an important economic factor. Why mixed cultures, even of the small grains, outyield pure cultures is an interesting phenomenon, and one can easily theorize to his heart's content. In nature plants are usually, but not always, in mixed cultures. Actually we know practically nothing of these phenomena except the observed or experimental facts.

Perhaps no one will contend that a graduate of the best botanical courses in America is thereby fitted to undertake the cultivation of any crop, let alone such as require special knowledge and skill. It is remarkable to how great a degree that success in growing a crop is based on the slowly accumulated results of experience. During the war you will remember there was urgent need for a large supply of castor beans. It is doubtful if in the whole history of American agriculture there was ever a more dismal failure than the attempt to produce these beans. There was an abundance of theoretical data based on the culture in other countries, but in attempting to grow the crop in the United States the handicaps of unadapted varieties and unexpected diffculties proved disastrous. Perhaps in no other industry is the advice "Make haste slowly" more applicable than in agriculture.

I have endeavored to point out by a few examples of plant cultural problems how different they are from those considered in the conventional botany of the schools. The 
methods of research developed in the laboratories hardly apply at all to the problems of plant culturist, a fact that the laboratory men have scarcely appreciated, and which has led them into a mental attitude disparaging toward the methods of the agronomist and horticulturist. It is not insignificant that the discoveries of Mendel, of Helriegel and Wilfarth. of Garner and Allard were made possible by problems revealed in the culture of plants and all were solved by the simplest of methods. Koelreuter's work in hybridization was largely inspired by his knowledge of garden plants, and was promptly utilized by horticulturists though ignored by botanists. One may well doubt whether laboratory botanists could ever have detected the meaning of the dance of the chromosomes; though I am not unaware thiat there were dim guesses as to what they might signify even before the revelations of modern Mendelism.

One of the phrases too often seen in print is " revolution in agriculture." The expression is almost purely rhetorical and not a statement of fact or even of approximation. In most cases large chianges in agriculture have been due to very simple things, usually the introduction of a new crop or the suddien expansion of an old one. Witness alfalfa in the west, sorghums in the southwest, rubber in Malaya, the sugar beet in Europe, the increase of cotton in the south following the invention of the cotton gin. I can recall nothing of comparable effect on agriculture resultant from a discovery in a botanical laboratory. It may be argued, truly enough, that the knowledge of bacteria has revolutionized modern medicine; but the credit for this advance can scarcely be claimed by botanists. Botany seems truly to have neglected its splendid opportunities in its adherence to the fetich of pure science.

It may be well to caution that in any attempt to unify botany and plant culture, the word botany will exercise no hypnotic influence. Rightly or wrongly the word does not convey to the public mind something highly desirable and useful. To the ordinary man a botanist is a more or less queer individual who goes about with a tin box over his shoulder collecting plants. Perhaps this had something to do with the loss of caste of taxonomy among botanists. It may be questioned, however, if the whittling of paraffine seations, or the use of strange apparatus in the woods and marshes, or the growing of fungi in test tubes will lead to a profoundly different evaluation of botany.

I trust that any frankness of expression that I have indulged in will not be interpreted as ill-will, but that it will be regarded as an effort to clear away the mist and to bring about better understanding. Much that has been written on the general subject seems to carry the impression that plant culturists have a stolidity that partakes of the ox, and do not wince at the reflections that come from the pens of botanists. It may be well to dispel any such assumption, which in my judgment has done incalculable harm to botany.

The points of my thesis are virtually three: (1) that our knowledge of plant culture is to a very large extent still almost purely empirical; (2) that there has been a lamentable tendency to consider plant culture and its methods of study as something apart from botany and not worthy of so high respect; and (3) that there has been proneness to claim for botany as well as for chemistry an undue amount of merit for what they have conitributed to agriculture.

I have, I believe, as much faith as any one in the services that plant science can render to mankind, and that not by furnishing bread alone. There is need, however, of broadening our vision and ideals, of freeing ourselves from any caste feeling, of recognizing that the human race is at least as much interested in food and food production as it is in the fate of the synergids, the origin of the angiosperms, or the genes of Capsella. For the good of all of us there is every reason to bring about a closer union of the societies interested in plants and their culture. Such a union will without doubt lead to better mutual understanding and reciprocal sympathy. At least we shall learn that most conventional botanists as well as plant culturists are, after all, to 
use the expressive slang of the day, "regular fellows."

The last few years have taught us all how small a reserve of food there is even in normal times. Largely as a result of the cataclysmic war famine now stalks over much of the earth. It needs no Malthus to convince us that an adequate food supply will become more and more the great problem of mankind. In spite of the haziness that envelops most of our present theories of productivity, one can scarcely fail to have faith that it is the half light that precedes dawn. The complex and obscure factors involved in crop production need for their solution a far greater number of botanically trained investigators. With clearer theoretical undenstanding of these factors, there is every reason to believe that the earth will be made to yield more abundantly. It is to this field of investigation so vital to human welfare, that I confidently hope botanists will more and more devote their energies, both as a matter of duty to mankind, and as an earnest of faith in their science and the services it can render.

Charles V. Piper

\section{SCIENTIFIC EVENTS}

\section{THE CARNEGIE TRUST FOR SCOTTISH} UNIVERSITIES

The British Medical Journal states that the annual meeting of the Carnegie Trust for the Universities of Scotland was held in a committee-room of the House of Lords, on February 9, with Lord Balfour of Burleigh in the chair. Lord Balfour said that the principal event of last year was the allocation of grants for the quinquennial period of 1920-25. In addition to the $\$ 200,000$ from income, it had been resolved to allocate from the reserve fund $£ 49,000$. The explanation. of this was that during the war the students at the universities were fewer, and therefore the trustees saved on the payment of fees. It would have been absurd to save that money and put it to the reserve, when many of the same students were coming back after the war and wanted it. The trustees thought it right, as a temporary measure, to take it out of the reserve fund, and give it to them to pay their fees, Under the research scheme it had been agreed that as an experiment for a period of three years the following annual grants be offered to the universities to be spent in payment of half the salaries of persons engaged as part-time assistants or lecturers on condition that they devoted not less than half their time to research, and that the universities should contribute the other half of the salaries from other sources-Glasgow and Edinburgh $£ 1,000$ each, St. Andrews and Aberdeen $£ 800$ each. It was hoped that much good to the universities would result from this combination of teaching and research, and the scheme had been well received by the universities. Although the amount available for assistance to students was now fully $£ 60,000$, there was a deficit of $£ 8,538$ for $1919-20$. The universities were now increasing their tuition fees, and as a result the poor student would be poorer than ever. Thus the difficulties were very great. For many years the trustees had been able to pay all eligible applicants the whole of their class fees, but in 1911-12 they had had to have an allowance system, because the income would not cover the whole of the fee, and since then the trustees had been paying only a part of the fees. The situation would be further changed in the current year owing to the increase in tuition fees.

The discussion in which Lord Haldane, Lord Sands, and others took part, centered chiefly in the problem of allocating assistance to the students. It was agreed that steps must be taken to eliminate from the beneficiaries of the fund those applicants whose circumstances were such as to render assistance unnecessary. Proposals were made for strengthening the declaration made by applicants and for an inquiry into individual circumstances. The suggestions were discussed, but a decision will not be reached until the alternatives have been further considered in the light of the views expressed by university authorities and others interested. 